\title{
The Reputation Trap of NGO Accountability*
}

\author{
Stephen E. Gent \\ Mark J. C. Crescenzi \\ Elizabeth J. Menninga \\ Lindsay Reid \\ Department of Political Science \\ University of North Carolina at Chapel Hill
}

January 29, 2013

\begin{abstract}
In this paper we examine the role of reputation in the behavior of nongovernmental organizations (NGOs). Can the pursuit and maintenance of a reputation cause NGOs to change their behavior in meaningful ways? Or are the norms and institutions that motivate and govern NGOs the sole drivers of behavior? To answer these questions, we focus on the relationship between NGOs and their donors. Our theoretical model reveals that reputation can be a key piece of information in the decision to fund the activities of a non-governmental organization. Indeed, reputation can become so important to the survival of the NGO that it interferes with the long-term policy goals of the organization. The resulting short-term NGO behavior is often misconstrued as incompetent or inefficient, but it is actually motivated by the structural constraints of the relationship with donors. We illustrate this strategic dynamic here with a focus on three types of NGO activity: international crisis mediation, ameliorating poverty, and water improvement.
\end{abstract}

\footnotetext{
${ }^{*}$ The authors would like to thank Leanna Miller, Scott Hiers, and Will Walker for helpful research assistance and attendees at the Steiner Seminar at UNC, the IR Research Colloquium at UNC, and the Lee/Bankard Seminar in Global Politics at the University of Virginia for valuable feedback on earlier drafts. A previous version of this paper was presented at the 2012 meeting of the Peace Science Society (International). This is a work in progress. Comments are welcome. Corresponding author: Stephen Gent (gent@unc.edu)
} 
In this paper we examine the role of reputation in the behavior of non-governmental organizations (NGOs). There is ample anecdotal evidence that indicates that NGOs care deeply about their reputations. Often the argument is made that both NGOs and their state-centered counterparts, intergovernmental organizations, rely on legitimacy as political currency. Lacking the classic mechanisms of power afforded to states, these organizations need alternate sources of influence. A solid and well communicated reputation perhaps offers an NGO such an alternate foundation to help it succeed in its goals.

The origins and influence of reputations, however, can only truly be understood in the context of interaction with others. Can the pursuit and maintenance of a reputation cause NGOs to change their behavior in meaningful ways, or are the norms and institutions that motivate and govern NGOs the sole drivers of behavior? To answer these questions, we focus our attention on the relationship between NGOs and their donors. We focus here on NGOs that are not self-sustaining, which means they rely upon grants and donations to fuel their budgets. Donors are defined as the principals who seek to fund agents (in this case, the NGOs) to accomplish policy goals on their behalf. The NGO-donor relationship is crucial to the existence and choices made by the internal governing body of any NGO that is not self-sustaining.

To focus on this NGO-donor dynamic, we develop a model of the interaction between donors and NGOs within the broad framework of a principal-agent problem. NGOs face constant pressure to maintain revenues from donors in order to survive and pursue policy goals. Donors, on the other hand, face the difficult task of investing wisely in NGOs that are capable of policy success. Reputation has an important role in this principal-agent dynamic. By shifting our attention to the strategic dynamics of the NGO-donor relationship, we find NGOs can have incentives to pursue strategies that maximize their reputations for competence in the eyes of their donors. These incentives can trigger important changes in performance (both real and demonstrated) and help us understand why NGOs struggle to balance their intrinsic motivations with the strategic imperatives that result from donor 
dependence.

Competent NGOs are those that are able to use the resources provided by the donors to achieve real, tangible progress toward policy goals. ${ }^{1}$ Competence, however, is not easily observed by donors, nor is it a stable condition. Policy successes, even short-term ones, provide meaningful signals of competence to donors. Donors then reward these signals with funds. A competent NGO will invest significant resources in the maintenance of its reputation, and the possibility of changes in competence means donors never stop caring about this reputation. In a world of uncertainty, reputation becomes an important part of the NGO-donor relationship that affects the activities of NGOs fundamentally.

The constant need to maintain a reputation for competence can constrain the focus of NGOs to the short term. The resulting myopic focus on small goals that are quickly and visibly accomplished can seemingly undermine the pursuit of the central goals of the NGO. What appears from the outside as incompetence is actually the opposite. Acting rationally, high quality NGOs and donors find themselves in what we term a "reputation trap." To survive financially, NGOs become frustratingly hobbled by their need to continuously produce tangible results to maintain their reputations. By requiring NGOs to provide such signals of their competence, donors do not aim to impede long-term policy successes. Rather, they simply wish to maximize the potency of their resources by only funding the "right" agents. Calls for transparency and accountability, long the hallmark of reform calls for NGOs, will not address these problems. Only by changing the structure of the NGO-donor relationship will these actors be able to escape the reputation trap and focus their a greater proportion of their efforts to long-term policy success.

We illustrate this strategic dynamic here with a focus on three types of NGO activity: international crisis mediation, water improvement, and ameliorating poverty. International mediation is a classically noble cause, emerging from the norms and institutions of non-violent conflict resolution in the international system (Bercovitch and Jackson 2009; Beardsley 2011;

\footnotetext{
${ }^{1}$ The conditions that define successful progress are a function of the task at hand, the NGO's preferences, and donors' preferences.
} 
Diehl and Grieg 2012). Using the insights of the model, we evaluate the behavior of the Centre for Humanitarian Dialogue (HDC) in its first attempts to secure peace in Aceh in 1999. As the HDC worked to produce cease-fire agreements in the Acehnese conflict, it also sought to establish its image and credibility as a competent, effective mediator. HDC's policy successes ultimately fell short of a durable peace, but proved to be sufficient to establish HDC's reputation as a successful mediator. We then highlight the short-term implications of the reputation trap, focusing on the challenges faced by NGOs in pursuit of improving water access and clean water. Water safety and access has emerged as one of the most pernicious problems of the 21st century. Water NGOs have ambitiously tackled these problems, but too often they are forced to settle for reporting the number of bore holes they produce instead of focusing their efforts on more permanent solutions.

Finally, we discuss the Bangladesh Rural Advancement Committee (BRAC) to illustrate the dynamic mechanics of our model as well as potential policy solutions to the reputation trap. The goal of ameliorating poverty ranks as one of the most pressing and salient activities of our age. The BRAC originated in the early 1970s with the goal of improving education, employment, and welfare of the poorest citizens of Bangladesh. BRAC's leadership stability has decelerated the decay of its historical reputation, and in recent years the BRAC has been able to balance its dependence on donors with self-sustaining funds. These two factors have partially mitigated BRAC's reputation trap and point to potential policy prescriptions for addressing these types of incentive problems faced by other NGOs.

\section{Reputation}

The literature on reputation in international relations first began to develop within the extensive works on deterrence theory (Schelling 1966). Theories of reputation, however, have evolved far beyond their original conceptions. Mercer (1996) pushed for a broader understanding of reputation, one that would apply beyond the Cold War notion of the term. Essential to Mercer's definition of reputation is that an observer uses dispositional attributes 
to explain the future behavior of others. Dispositional attributes such as reliability, resolve, or competence are expected to be valid regardless of the situation. Copeland (1997), however, extends the definition of reputation further to include situational factors, explaining behavior based on context; what one actor does in a particular scenario, most others would do as well. Beyond the debate over dispositional versus situational attributions, a more general definition of reputation can arise. Reputation describes a phenomenon where actors: (1) learn from and interpret observations and then update their beliefs, and (2) use updated beliefs to influence their international behavior (Jervis 1976; Levy 1994; Crescenzi 2007).

Reputation serves two primary functions in international politics. First, actors strive to build a reputation because it gives them the ability to separate or distinguish themselves from the crowd. For example, Bercovitch and Schneider $(2000,146)$ describe how mediators are "interested in the prestige that they could gain from successful mediations." Mediators who seek a reputation are trying to establish that they are more capable than alternative actors. In this way, international mediators behave in much the same way as firms. Mailath and Samuelson $(1998 ; 2001)$ assert that while firms have short-term incentives to exert low effort, they would earn higher profits in the long run if they would commit to high effort instead. Reputation provides a mechanism that allows firms to signal that they are worth the investment; competent firms expend extra effort to maintain a reputation that sets them apart from inept firms. In our analysis, we examine how NGOs have similar incentives to build and maintain a reputation for competence in order to guarantee continued funding from donors.

Reputation also serves a second function for actors: it disseminates information about future behavior (Walter 2003; 2006). Actors synthesize these observations and perceptions over time, creating their own realities (Jervis 1988, 694). They absorb information and learn from it; as such, reputations have the ability to alter future behavior. This reputational information has been shown to influence state decisions about conflict behavior, escalation to war, and alliance formation (Crescenzi 2007; Crescenzi, Kathman and Long 2007; Crescenzi 
et al. 2012). We investigate the extent to which this kind of information dissemination is relevant for the decisions NGOs make about their own behavior. Our intuition is that that reputation may be even more important for NGOs than it is for states, particularly with they do not possess internal mechanisms for financial survival.

As a phenomenon that is largely based on observations and perceptions, reputation is generally considered to be an abstract concept. Given its abstract nature, reputation's importance is not universally accepted. Press (2004), for example, states that the scholarly research that hails reputation as a key variable in decisions and actions is "based on a dubious leap from behavior in daily life to decision-making in life-and-death crises" (139). Press urges that leaders use current calculations in times of crisis to make decisions; reputational information has no presence in their decision-making. The assertion that reputation is an irrelevant variable for the behavior and decisions of actors is ultimately an empirical question, but before that question can be accurately examined we need to have a logically consistent argument that ties reputational information to political behavior.

Lastly, a reputation is dynamic; it is subject to both gradual changes and sudden shocks that lead to rapid updating. Reputation evolves for several reasons including but not limited to leadership changes, new experiences, and/or missed opportunities. Older information about reputation holds less weight than newer information when it comes time to make decisions. Newer information is more relevant than the distant past because newer information generates signals that better reflect the current reputation of an actor. Actors recognize the impact that time has on reputation, and they have an incentive to continually work at maintaining their reputation over time. In the case of NGOs, the potential for high variability in staff and resources can accelerate the degradation of old information. In the theory we develop below, we take these temporal dynamics into account. 


\section{NGO Accountability}

While the success or failure of NGOs in the broader category of international organizations has been widely examined in the international relations literature, this discussion typically focuses on the existence, utility, and performance of NGOs. These lines of research have roots in grand theory debates (Waltz 1979; Keohane 1984), and more recently, scholars have examined NGOs from a sociological perspective (Finnemore 1996; Barnett and Finnemore 1999; 2004; Sundstrom 2005). Typically, these studies focus on the role of the NGO in the international system, its objectivity or autonomy from states in the system, or the ability of the NGO to have an impact in world politics. Norms and the socio-political environment shape or construct the emergence, goals, and activities of NGOs, often encouraging (or constraining) these organizations to engage in behavior that may appear to be irrational or subjective.

To examine the role of reputation in NGO behavior, however, we turn to reputational theories of the firm (Kreps and Wilson 1982; Milgrom and Roberts 1982; Fudenberg and Levine 1989; 1992; Mailath and Samuelson 1998; 2001). Although NGOs are not profitdriven enterprises, they have substantial similarities with firms. Cooley and Ron (2002) argue that NGOs respond to contractual incentives and organizational pressures much like firms in markets. Although NGOs might not be profit driven, the need to secure a steady source of funding and contracts shapes their decision-making process and actions within the NGO market. Thus, the NGO market operates with similar competitive pressures encouraging NGOs to actually compete with each other instead of work together toward a common goal.

Johnson and Prakash (2007) identify similarities between the donor-NGO relationship and the stockholder-firm relationship. Primarily, both relationships are plagued by the same principal-agent problem. Just as stockholders and firms share the common goal of maximizing profits, donors and NGOs are also connected by a common goal. Such a principal-agent focus on NGOs and their donors has received criticism in the past. Barnett and Finnemore (1999) argue that the principal-agent framework is inappropriate because the donor and the 
organization have the same preferences, but an assumption that donor and NGO preferences are identical is incomplete and problematic. While the donors and NGOs have similar enough preferences to work together (like firms and stakeholders), donors still have to worry about the efficient use of resources as well as any short-term divergences in preferences.

While there are many advantages to working through or with NGOs, identifying effective NGOs can be a difficult task for donors (Boulding 2009). Many high quality NGOs recognize this difficulty and attempt to signal their quality to potential donors by taking costly actions such as creating and joining voluntary accountability and standard setting programs (Gugerty 2009; Reinhardt 2009). Given that many of the activities of NGOs are not observed by donors, uncertainty about the effectiveness of NGOs often continues to persist even after the donor-NGO relationship is established. To alleviate potential principal-agent problems that could result from such uncertainty, donors and NGOs often turn to the establishment of accountability mechanisms. Accountability refers to "the means by which individuals and organizations report to a recognized authority (or authorities) and are held responsible for their actions" (Edwards and Hulme 1996, 967). To resolve information asymmetries, NGOs typically generate product data, such as standardized reports, that are transmitted to donors (Ebrahim 2002). In practice, these tools, which include disclosure reports and performance assessments, are the primary means by which NGOs are held accountable to their donors (Ebrahim 2003).

Of course, NGOs can be potentially accountable to many different actors, including donors, clients, and themselves. However, in practice, NGOs have primarily focused on "upward" and "external" accountability to donors, largely ignoring accountability to other actors (Najam 1996; Ebrahim 2003). In addition to the actor they target, accountability measures vary in the organizational responses they engender. Functional mechanisms account for resources, resource use, and immediate impacts, while strategic mechanisms account for the impacts that an NGO's activities have on the actions of other organizations and the wider environment (Najam 1996; Ebrahim 2003). Empirically, NGOs have placed more emphasis 
on the former measures, which lead them to prioritize short-term goals. For this reason, many scholars and practitioners have argued that a focus on functional accountability to donors has led to organizational practices that do not effectively achieve the long-term political and social goals of NGOs (Najam 1996; Ebrahim 2003; 2005; Jordan 2005; O’Dwyer and Unerman 2007; 2008). Nevertheless, despite the potentially poor long-term consequences, we do observe that NGOs and donors commonly implement functional accountability measures. The theoretical model developed in the next section aims to explain why and when NGOs and donors would rationally choose to do so. Later, in our discussion of the empirical behavior of international NGOs in several issue areas, we explore the potential inter-temporal tradeoffs that can result from the establishment of such accountability schemes.

\section{Theoretical Model}

Our theoretical model focuses on the principal-agent relationship between a donor and a non-governmental organization. The donor chooses whether to fund an NGO to pursue a particular policy. If the NGO receives funding, it decides how much effort to put into achieving the donor's proposed policy versus pursuing other activities. Like many gametheoretic models of reputation, we assume that the principal is uncertain about both the type and the actions of the agent (Fudenberg and Levine 1992; Mailath and Samuelson 2001). First, the donor does not know the competence level of the NGO. This can potentially lead to adverse selection, in which the donor funds an incompetent NGO that cannot produce

successful policy outcomes. Second, while the donor can observe the policy outcomes of the NGO's activities, it cannot observe the level of effort exerted by the NGO. This can potentially lead to moral hazard, in which the NGO puts little effort into achieving the donor's goals because its funding is not dependent upon its effort level.

Unlike many of the canonical game-theoretic models of reputation (e.g. Kreps and Wilson 1982; Milgrom and Roberts 1982; Fudenberg and Levine 1989; 1992), we do not allow for the possibility that the agent is a "commitment" type who will always exert high effort. In such 
models, ordinary agents maintain a reputation by mimicking such commitment types. This "negative" conceptualization of reputation, which implies that agents are rewarded with a good reputation by pretending to be someone that they are not, appears inconsistent with our understanding of how reputations are developed empirically. Instead, our model only allows for the possibility that the agent is an incompetent type that is unable to (or is never willing to) exert high effort. Thus, competent agents develop and maintain a reputation by separating from incompetent types. In this "positive" conceptualization of reputation, agents earn a good reputation by demonstrating to others who they really are.

Mailath and Samuelson $(1998 ; 2001)$ demonstrate that the creation of a reputation through separation requires perpetual uncertainty about the agent's type. In our model, we allow for the possibility that the NGO's level of competence changes over time through exogenous shake-ups. These exogenous shake-ups can take on several forms. Perhaps the director of the organization has retired, handing over the NGO to new leadership. On the opposite end, large turnover among staff could decrease the competence and efficiency of the organization as new staff is trained. Additionally, new technology could be discovered (or acquired) by the organization improving productivity and efficiency, positively influencing the NGO's type. Some possibility of such a shake-up is always possible in an NGO, and the consequences of these internal changes are often unobservable to donors.

To focus our analysis on reputational dynamics, we assume that an NGO is primarily interested in maintaining its funding, rather than achieving successful policy outcomes. Obviously this assumption abstracts from empirical reality, but it is appropriate for several reasons. First, it allows us to isolate the effects of reputation from other potential motivating factors for NGO behavior. Second, NGOs do care about funding, as they rely upon it for survival. Without funding, an NGO would not even have a chance to pursue policy goals. In this way, the assumption that NGOs care about funding is similar to the common assumption that politicians care primarily about staying in office. Finally, one can indirectly incorporate the role of policy salience into our model through the cost term. In particular, one would 
expect that NGOs that care more about the relevant issue would have lower marginal costs of effort than those that do not. Thus, as long as one does not assume that altruism or salience leads NGOs to always pursue high effort, our model can take into account both the monetary and policy interests that influence NGO decision making.

Our theoretical model includes two players, a donor and an NGO. The NGO can be one of two types $(\tau)$ : competent $(C)$ or incompetent $(I)$. Competent NGOs have the ability to pursue successful policies, while incompetent NGOs do not. At the beginning of the game, Nature chooses the type of the NGO. The NGO is competent with probability $\theta \in(0,1)$ and incompetent with probability $1-\theta$. The NGO learns its type, while the donor does not.

In each period, the donor decides whether to fund the NGO. If the donor chooses not to fund, the NGO ceases to exist and the game ends. If the donor funds, it transfers a lump sum, $f$, to the organization. A competent NGO then decides the level of effort to put into achieving a successful policy outcome in that period. In particular, it can expend a high level of effort $(H)$ at a cost $e>0$ or a low $(L)$ level of effort at no cost. To allow for the possibility that the NGO would be willing to exert high effort, we assume that the cost of high effort does not exceed the per-period funding available from the donor (i.e., $e \leq f)$. We assume that an incompetent NGO can only expend a low level of effort. The donor does not observe the amount of effort expended by the NGO.

After the NGO chooses the level of effort, Nature then determines the policy outcome for the period, which can be either successful or unsuccessful. If the NGO chooses a high level of effort, there is a successful outcome with probability $\pi$ and an unsuccessful outcome with probability $1-\pi$. For simplicity, we assume that low effort always results in an unsuccessful outcome. $^{2}$ The policy outcome is observed by all players. We assume that donors receive a payoff of 1 for a successful outcome and 0 for an unsuccessful outcome. NGOs do not receive any direct payoff for the policy outcome.

\footnotetext{
${ }^{2}$ Though the analysis would be more complex, we expect that one would obtain similar substantive results in a model in which success is possible after low effort, as long as the probability of success is higher after high effort than after low effort.
} 
Play continues until the donor decides not to fund the NGO. In all subsequent periods after the first period, we assume that there is the possibility of an exogenous "shake-up" in the NGO with probability $\lambda$. For example, there could be a change in personnel or leadership of the NGO. In the event of a shake-up, Nature redetermines the NGO's type. In particular, after a shakeup, the NGO is competent with probability $\theta$ and incompetent with probability $1-\theta$. We assume that any shakeup is unobserved by the donor. Finally, we assume that the donor is myopic, so it only cares about its payoff in the current period (i.e., it has a discount factor of 0 ). We expect that donors will be interested in getting a return on their investment in a given period before they consider whether to renew an NGO's funding. On the other hand, since the NGO is concerned with survival, it discounts future payoffs with a discount factor $\delta \in(0,1)$.

Given that we assume that the donor is myopic, we limit our analysis to Markov strategies, which only depend upon payoff-relevant histories. Let $\mu$ be the donor's belief that the NGO is competent, and let $\sigma(\mu)$ be the probability that a competent NGO will exert high effort given that belief. Then the donor expects to receive a successful policy outcome in a given period with probability $p(\mu)=\mu \sigma \pi$. Since the donor is myopic and the utility of a successful outcome is 1 , it will choose to fund if $p(\mu) \geq f$.

Consider a situation in which competent NGOs always exert high effort. In this case, policy outcomes can provide information about the NGO's competence. The donor's posterior belief that the NGO is competent in a given period is a function of its prior belief, the policy outcome in the previous period, and the probability of a shake-up. After a successful policy outcome, the posterior belief is:

$$
\mu_{s}=1-\lambda(1-\theta)
$$

Since only competent NGOs can be successful, a successful outcome in the previous period indicates that the NGO was competent in the previous period. However, there is some probability, $\lambda(1-\theta)$, that a shakeup in the current period will result in the the NGO being 
incompetent. Thus, if $\lambda>0$, the donor can never know with certainty whether the NGO is competent in the current period. On the other hand, the donor's posterior belief that the NGO is competent after an unsuccessful outcome is:

$$
\begin{aligned}
\mu_{u} & =(1-\lambda)\left[\frac{(1-\pi) \mu}{(1-\pi) \mu+1-\mu}\right]+\lambda \theta \\
& =(1-\lambda)\left[\frac{(1-\pi) \mu}{1-\pi \mu}\right]+\lambda \theta
\end{aligned}
$$

If $0<\mu<1, \mu_{s}>\mu_{u}$. Thus, as long as there is uncertainty about the NGO's competence, the donor's belief that the NGO is competent is higher after a successful policy outcome than after an unsuccessful outcome. In addition, it can be shown that the donor's belief that the NGO is competent decreases after an unsuccessful outcome. If we let $\hat{\mu}$ be the fixed point at which $\mu_{u}=\mu$ (such that $0<\hat{\mu}<1$ ), it follows that the $\hat{\mu}$ is the lowest possible belief about the NGO's competence that the donor can have.

If there is no possibility of a shakeup (i.e., $\lambda=0$ ), a competent NGO will never choose to exert high effort. To see why this is the case, consider the situation in which the donor believes the NGO to be competent $(\mu=1)$. In this case, $\mu_{s}=\mu_{u}=1$. Because the donor assumes that any unsuccessful outcome is due to bad luck, rather than low effort, it will believe the NGO to be competent regardless of the policy outcome. Thus, the NGO has no incentive to choose high effort since it would be funded in any case. In addition, there cannot be an equilibrium in which the competent NGO chooses low effort when $\mu=1$ but chooses high effort at other values of $\mu$. In such an equilibrium, the donor would not fund if $\mu=1$. Since $\mu_{s}=1$, the NGO knows that it will not be funded in the next period if there is a successful outcome. Given this, the NGO would have no incentive to pay the cost of high effort because it would cease to exist after a successful policy outcome. Thus, as Mailath and Samuelson $(1998,2001)$ show, separation between competent and incompetent agents can only occur if there is perpetual uncertainty about the agent's type. In our model, this implies that high effort by competent NGOs can only occur in equilibrium if $\lambda>0$. The 
next proposition identifies the conditions under which there will be high effort.

Proposition 1. If the cost of effort is sufficiently small, $\lambda>0$, and $f>\hat{\mu} \pi$, there exists a Markov perfect equilibrium in which a competent NGO always chooses high effort.

The formal proof of the proposition can be found in the appendix. The intuition is as follows. If competent NGOs will exert high effort, the donor will be more willing to fund competent NGOs than incompetent NGOs. Thus, the donor's equilibrium strategy will depend upon its belief that the NGO is competent. In particular, there will be a cutpoint, $\mu^{*}$, such that the donor will fund if $\mu \geq \mu^{*}$ and not fund otherwise. Due to the possibility of a shake-up in each period, the donor can never know the NGO's type with certainty. Since successful outcomes are only possible with high effort and only competent types exert high effort, the donor's belief that the NGO is competent is higher after a successful outcome than after an unsuccessful outcome. Because the NGO would prefer to maintain its funding, it has an incentive to prevent the donor's belief from falling below $\mu^{*}$. Since, in expectation, higher effort will produce a higher belief than lower effort, the NGO will pursue a high level of effort if the cost is sufficiently low.

The theoretical model provides insight into the potential role that reputation can play in the relationship between donors and NGOs. One can consider the parameter $\mu$, the donor's belief that the NGO is competent, to be the NGO's reputation. Because donors cannot directly observe the competence of an NGO, they must make their funding decisions based upon an NGO's reputation. In particular, donors are only willing to fund NGOs with good reputations $\left(\mu \geq \mu^{*}\right)$. If an NGO's reputation falls too low, a donor will cut off its funding.

In the model, an NGO's reputation is based upon its record of policy successes. Because donors cannot directly observe all of the actions of an NGO, they do not know the precise effort level that the NGO puts into its activities. However, they can observe whether the NGO's efforts lead to successful policy outcomes. For example, a donor might not know how much effort a NGO put into mediating a civil war, but it can observe whether the mediation led to a peace agreement. Thus, a donor updates its belief about the competence of an NGO 
after each policy success or failure. If success is only possible when a competent NGO exerts a high level of effort, an NGO can quickly develop an excellent reputation after a policy success. On the other hand, a series of policy failures would gradually erode the NGO's reputation. After a sufficient number of failures in a row, the donor will begin to believe that the NGO is incompetent and will cut off the NGO's funding.

These reputation dynamics thus influence the behavior of NGOs. To maintain its funding from donors, a competent NGO will attempt to build and maintain a good reputation by putting more effort into activities aimed at achieving the donor's policy goals. It expects that such efforts will lead to more successful policy outcomes, which will in turn increase the donor's belief that NGO is competent. However, according to the model, for such reputational concerns to influence the behavior of NGOs, there must always be some uncertainty on the part of the donor. If the donor knows with certainty that an NGO is competent, there is nothing for the NGO to prove, as there is no outcome that would decrease the donor's belief that it is competent. However, if there is always a possibility that a shake-up in the organization - due to staff turnover or new challenges in the international policy arena-can affect the NGO's ability to pursue successful policies, the donor can never know with certainty the competence of the NGO. Thus, the NGO will always have something to prove to its donors and will continue to have an incentive to put a high level of effort into its activities to maintain a good reputation.

This reputation process can provide a useful accountability mechanism for donors. Given the information asymmetries inherent in donor-NGO relations, donors aim to avoid problems of adverse selection, in which they fund incompetent NGOs, and moral hazard, in which NGOs fail to put sufficient effort into the donor's policy goals. From the perspective of the donors, however, identifying policy successes can be very difficult. The overall objectives of international NGOs are often very grandiose, and achievement of these long term goals is not arrived at quickly. Evaluating signals of competence and effort throughout the process is important to ensure donors their money is not being wasted and that additional financial 
support would be put to good use. For this reason, donors may look for tangible positive achievements that are more feasible in shorter time windows. These shorter time windows would allow donors to more frequently observe and evaluate the effectiveness and competency of an NGO, updating their beliefs and thus their funding decisions accordingly.

However, while the reputational accountability mechanism can help overcome problems such as adverse selection and moral hazard, it can also create perverse incentives for NGOs. In order to maintain funding, competent NGOs must put effort into activities that will lead to tangible policy successes observable to donors. While these short-term successes can provide signals of a group's competence, they do not necessarily indicate progress the longterm goals of the organization. For example, an NGO focused on health care in a developing country may promote the number of successful medical procedures that it is has performed in a country as a signal of its competence. However, this metric provides no information on the organization's impact on the overall level of health in the country. Moreover, because the organization must signal competence to its donors, it may focus its attention on maximizing the number of medical procedures performed rather than pursuing other activities, such as preventative health programs, that do not produce tangible short-term results but might be more effective at achieving the group's long-term goals. In this way, short-term goals can override long term foci, leading an NGO to engage in behavior that appears to impede the "big-picture" progress of the group.

We call the situation described above a reputation trap. To survive, NGOs must continually focus on the task of demonstrating competence. However, in doing so, they divert their attention away from achieving their long term goals. The trap is not created by incompetence or irrationality; instead, it is the result of rational decisions made by donors and NGOs. In attempting to resolve one set of principal-agent problems, donors inadvertently create a new set of perverse incentives for NGOs. As such, reputations can become a double-edged sword for NGOs, simultaneously providing the information donors need to commit resources while constraining the NGO from maximizing its pursuit of its policy goals. In the next section, we 
illustrate the reputational dynamics identified in our theoretical model with a focus on three types of NGO activity: international crisis mediation, water improvement, and ameliorating poverty.

\section{Empirical Illustrations}

We now turn to three empirical cases that highlight the various dynamics and implications of our theoretical argument. ${ }^{3}$ In the first case we examine the Center for Humanitarian Dialogue's efforts to mediate a civil conflict between the Free Aceh Movement and the Indonesian military. This case highlights the importance of reputation early on in the existence of an NGO, and the structural pressure on the NGO to identify and report tangible accomplishments. Our second illustration focuses on water NGOs and their efforts to improve water access. The activities of these NGOs show how the need for reporting quantifiable short-term results can undermine the ability to achieve durable policy progress. Lastly, we trace the evolution of the Bangladesh Rural Advancement Committee and shed light on a strategy that NGOs can use to potentially mitigate the reputation trap.

\section{Mediation: Centre for Humanitarian Dialogue and conflict resolu- tion in Aceh, 1999-2003}

The Centre for Humanitarian Dialogue is a nongovernmental organization that began its operations in August of 1999. Headquartered in Geneva, Switzerland, HDC works across the globe "to develop and strengthen a universal, intercultural and multidisciplinary dialogue in which all players concerned by humanitarian issues can exchange their experiences; and to devise and promote sustainable solutions to humanitarian problems" (Barakat, Connolly and Large 2002, 6). HDC strives to achieve its humanitarian goals first and foremost through conflict mediation. As a non-profit organization, HDC's mission is made possible

\footnotetext{
${ }^{3}$ These cases should not be considered as tests of hypotheses derived from our theory (as they were not selected quasi-randomly), but rather as targeted illustrations of the abstract model.
} 
by the support of donors ranging from countries such as Norway, Switzerland, and Canada to other organizations such as the United Nations Development Program, the International Committee of the Red Cross, and the MacArthur Foundation (HDC Annual Report 2009).

A brief look at HDC's role in Aceh illustrates how HDC worked to establish and improve its reputation as a qualified and capable conflict mediator. Although HDC has been the key mediator in a number of civil conflicts, we focus on the Acehnese conflict for two primary reasons. First, the mediation efforts in Aceh were HDC's first mediation attempt. Without previous experiences to bias or influence its reputation, we are able to assess the effect that their early actions and successes in Aceh had on their ability to develop a reputation for competence. Second, HDC was the only mediator active in Aceh at the time. Thus, we are able to attribute any successes and failures that occurred during those years to HDC.

The Indonesian region of Aceh has experienced continuous conflict since the middle of the 20th century. Social cleavages led to a major rebellion between 1953 and 1962, known as Darul Islam. The Darul Islam rebellion sought Acehnese regional autonomy over education, religion, and traditional laws. Although the central government granted autonomous status to the region in 1959, autonomy was never a reality in practice. Thus, in 1976, the Free Aceh Movement (GAM) rose to prominence and declared Acehnese independence (Huber 2004). The ideology of GAM is one of national liberation; specifically, GAM aimed to free Aceh from the political control of the foreign regime in Jakarta (Schulze 2004, 6). Violence continued throughout the region and then intensified following the resignation of the authoritarian Indonesian President Suharto in 1998. By 2000, the Acehnese conflict had attracted the attention of mediators who hoped to finally bring peace to the region (Huber 2004). Because the conflict in Aceh was secessionist in nature, HDC faced a particularly challenging mediation. HDC's drive to create a competent and successful image as a mediator influenced the very presence of HDC in Aceh. HDC cherry-picked Aceh over other conflicts because of the potential this particular conflict held for building a reputation. HDC had originally considered intervention in East Timor, but choose Aceh as "the density of aid 
agencies already present in East Timor following its independence led the HDC to seek a different venue" (Leary 2004, 315). Furthermore, HDC wanted to mediate a salient conflict; if this particular conflict could be successfully mediated, then the rewards to HDC would be paramount. HDC also attempted to signal high effort levels in the way that its staff comported themselves throughout the mediation process. Accounts from interviews indicate that the staff of HDC went above and beyond the call of duty to foster a successful mediation environment (Leary 2004). Louisa Chan-Boegli was one of the top conflict mediators for HDC throughout its work in Indonesia. Interviews reveal that she would regularly pick up members of each side of negotiations from the airport herself, eat dinner with them on alternating evenings, and stay up into the early morning working with the Indonesian groups (326). In the eyes of donors, however, signals of high effort like these are only cheap talk. While they are indicators of increased time spent with the disputants, donors cannot know if these efforts were sustained throughout the negotiations or only intermittently for increased publicity. Moreover, increased time with the disputants does not necessarily indicate that the mediators were capable of using this time to effectively bring the conflict to a resolution. Tangible results in the form of public negotiations, agreements, and ceasefires are of greater importance to donors in terms of evaluating the competence of mediators.

When HDC entered the country in 1999, it focused efforts on creating a ceasefire. In 2000, HDC was able to establish just that; the ceasefire agreed upon in 2000 is known as the "humanitarian pause" and held sporadically until 2001. In 2002, HDC facilitated a major breakthrough with the signing of the Cessation of Hostilities Agreement (COHA) (Huber 2004). COHA broke down by May 2003 (Morfit 2007, 112). Despite HDC's determination, it left the Acehnese conflict without mediating a lasting peace agreement. Although the peace ultimately did not last in Indonesia, the agreements represented positive progress perceived by the international community and donors as policy successes. The humanitarian pause, for example, was a success because it signaled that HDC had been able to organize face-to-face dialogue between belligerent groups and generate cooperation, however fleeting. Donors, 
viewing the ceasefire as a tangible form of success, credited HDC as a competent mediator that was worthy of continued funding. ${ }^{4} \mathrm{COHA}$ was an even greater breakthrough for HDC's reputation as a competent mediator. This second agreement was a more comprehensive ceasefire agreement that included provisions for demilitarization, all-inclusive dialogues regarding autonomy, and provincial election in Aceh (Huber 2004, vii). Norway's donations to HDC during this period supports this argument and demonstrates how donors responded to HDC's results in Aceh. As HDC was a nascent organization when it first decided to mediate in Aceh, Norway's funding in 1999 was limited. Only after HDC secured the humanitarian pause in 2000 did Norway begin providing additional funding for monitoring and humanitarian purposes.

HDC continues to maintain a reputation as a competent mediation NGO today, in spite of the initial difficulties it experienced in Aceh. This case highlights that organizations like HDC are able to spin positive steps, however fleeting, as indicators of success. Competent organizations do not always achieve success in absolute terms, but they do exert effort to achieve shorter-term tangible results and demonstrate to donors that they are worthy of continued support. Donors, whose funding generally comes on an annual basis, are encouraged by positive signals and renew funding even if the positive signals do not ultimately result in overall objective completion. These incentives to demonstrate competence can sometimes encourage NGOs to prioritize short-term policy progress over their broader objectives. In the case of HDC, the preferences of the organization and the donors aligned so that while HDC was concerned with achieving policy success quickly, it did not have to sacrifice its long-term goals to achieve these short-term signals. These conflicting short and long-term incentives, however, can potentially hurt the NGOs overall mission, as seen in the case of water NGOs discussed next.

\footnotetext{
${ }^{4}$ HDC's Annual Report from 2001 supports the conclusion that donors reacted positively to the "successful" signal created by the humanitarian pause. Funding jumped from CHF 4,624,300 in 2000 to CHF $5,756,000$ in 2001.
} 


\section{Water: Counting boreholes at the expense of sustainable water infrastructure}

Increasing access to clean water, one of the UN's Millennium Development Goals, is at the forefront of many policymakers' and human rights groups' agendas. Unfortunately, NGO concerns about donor perceptions of competence and the myopic evaluation of NGO success by donors prevent NGOs from focusing on long-term sustainable solutions to increasing clean water access worldwide. Instead, these NGOs are trapped in a system of short-term solutions that improve water access temporarily but do not address obstacles to long-term water availability. We focus in particular on one widely used program of water NGOs: borehole ${ }^{5}$ drilling.

As highlighted by Calow et al. (1997), the best source of clean water in many areas that struggle with water availability is ground water. Ground water tends to be rather abundant, annually replenished, and, perhaps most importantly, naturally protected (244). Boreholes, therefore, provide a quick, low-cost means to increase the number of water access points in a region by taking advantage of pre-existing groundwater reserves. New boreholes have several immediate advantages. More proximate access decreases the burden of attaining water by reducing the number of hours spent walking to an access point. Furthermore, by making water more accessible, boreholes help improve health outcomes, especially for children (Carter, Tyrrel and Howsam 1999).

While boreholes help achieve NGOs' goals in the short-term, they are very inefficient as improper planning and maintenance result in high rates of borehole failure. Boreholes fail for a number of reasons, including groundwater drought, contamination, and broken equipment. According to a UNICEF report, in 1995 twenty-five percent of wells and boreholes in Malawi were out of operation, malfunctioning, or dry (referenced in Calow et al. 1997). In Mali, the World Vision International initiative to build boreholes had a success rate of forty-one percent if success is defined as percent of boreholes in use by the community. When success

\footnotetext{
${ }^{5} \mathrm{~A}$ borehole is a small-diameter well drilled to access water.
} 
is defined as the percent of boreholes reaching the World Health Organization's minimum flow rates, this success rate drops to a mere ten percent (Gleitsmann, Kroma and Steenhuis 2007). Calow et al. (1997) argue that many of these failures are a result of predictable variations in groundwater drought vulnerability and that boreholes that fail as a result of equipment problems could be more easily and more quickly repaired if information on the location and functionality of existing boreholes was gathered and updated.

The long term efficiency of the water projects could therefore be improved if common factors that lead to borehole failure, such as groundwater drought, were accounted for in designing water programs. For example, in Malawi, boreholes were frequently built in areas vulnerable to groundwater drought. As these vulnerabilities were unaccounted for by the NGOs implementing the programs on the ground, when drought hit, many boreholes dried up. New boreholes constructed in response to the drought were also poorly planned and soon failed when the return of rain caused them to sink (Calow et al. 1997, 250). Thus, additional planning and research by NGOs before beginning new projects could lead to more sustainable, long-term program success.

Despite these known short-comings, tens of thousands of wells and boreholes are added every year in Africa alone (Skinner 2009). Program evaluations conducted by WaterAid, a leading international water NGO, acknowledge the need for sustainability, but the evaluations still focus on the generation of new access points (WaterAid 2010). Due in part to adverse incentives generated by the donor-NGO relationship, NGOs continue to concentrate their efforts on digging new boreholes instead of diverting resources to research and maintenance of existing holes. NGOs do not prioritize data collection because attracting donor support for such activities is difficult (Calow et al. 1997, 255). NGOs need to generate tangible progress toward their objectives that will signal their competency. Building boreholes generates quantifiable benefits with verifiable indicators of success. Data collection and research improve the chances for long-term improvements in water availability but are much more difficult for NGOs to use as signals of policy success (and thus of their competency). 
Water NGOs therefore prefer to deal with immediate, tangible problems with immediate, tangible solutions. Unfortunately, as NGOs have limited resources, a focus on increasing access points often precludes investment in more preventive or sustainable measures. Thus, water NGOs have found themselves in a trap where to signal policy successes to donors they are stuck engaging in short-term behavior that has some positive effects for their policy objectives but prevents them from achieving greater long-term progress in making clean water available worldwide.

Leading NGOs, like WaterAid, are trying to increase the sustainability of their projects and at least partially escape this trap. WaterAid's 2012 annual report highlights work being done in Nicaragua to train members of the community in which boreholes are drilled to maintain and repair these holes (WaterAid 2012). These efforts, however, are still restricted to easily quantifiable tasks. Their report cites numbers like "13 communities trained" and "46 water points rehabilitated" in Nicaragua (20). These efforts are moves in the right direction but are not sufficient to overcome the trap entirely. The World Vision International efforts in Malawi included community involvement and training but still saw such low success rates (Gleitsmann, Kroma and Steenhuis 2007). Training and maintenance after the borehole is dug can only help solve some of the problems with boreholes outlined above. Repair cannot resolve groundwater drought or sunk wells. More research on the optimal locations of these boreholes before they are dug is needed to really achieve sustainability.

Despite positive efforts by water NGOs, escaping the trap might require external assistance. Fortunately, groups like The International NGO Training and Research Center (INTRAC) have taken an interest in NGO performance, especially helping NGOs evaluate their efforts based upon programs' long-term impacts. Adams (2001), for example, considers water NGOs and finds that performance evaluations often described the NGOs' activities rather than analyzing the effectiveness of these activities, essentially highlighting the current standard practice of NGOs to evaluate programs' short-term progress instead of long-term value. Adams acknowledges that effectiveness is often difficult to identify and that many 
factors influence "success." Evaluating programs based upon long-term outcomes is a challenge. While acknowledging these challenges, Adams proceeds to begin establishing protocols and methods that would enable water NGOs to overcome these challenges. If groups like INTRAC can help generate metrics for water NGOs to quantify their programs' long-term impact, then NGOs concerned with the sustainability of their efforts will be able to signal long-term policy successes to donors in a tangible way. This could help NGOs signal competence without sacrificing long-term objectives for short-term gains.

\section{Development: The Bangladesh Rural Advancement Committee}

BRAC is a Bangladesh-based development NGO that is recognized as one of the largest organizations of its kind in the world (Chowdhury and Bhuiya 2001, 371). In discussing the development and activities of BRAC below, we shift to a more optimistic view of NGO reputation. While the dynamics of the NGO-donor relationship often create incentives for NGOs to pursue short-term goals in order to signal success to donors, BRAC demonstrates that NGOs have opportunities to mitigate the effects of the funding trap. After years of success and growth for BRAC, the organization has been able to begin self-financing most of its programs. As such, BRAC demonstrates not only the dynamics of reputation but also the potential for NGOs to mitigate the reputation trap by reducing donor dependency.

Founded in 1972 by Fazle Hasan Abed, BRAC emerged following Bangladesh's War of Independence. As its original name - the Bangladesh Rehabilitation Assistance Committeesuggests, BRAC's initial goal was to aid and rehabilitate the millions of refugees who were flooding back to the war-torn country from neighboring India. By 1973, however, BRAC changed its name to the Bangladesh Rural Advancement Committee. With this shift, BRAC indicated that the organization had new and wider goals. More recently, BRAC has adopted the motto, "Building resources across communities" (Smillie 2009, 3). Since its initial name change in 1973, BRAC's primary objectives have been the broad-based alleviation of poverty and empowerment of impoverished groups (BRAC 2013). 
From an organization of less than ten employees in 1972 (Smillie 2009, 25), BRAC has grown to employ over ninety thousand people (BRAC 2013). BRAC's tremendous growth provides a compelling illustration for our theory of reputation. At the time of BRAC's foundation, numerous relief organizations were flocking to the newly independent Bangladesh. BRAC, however, stood out from the crowd in its efforts. After over forty years of work, BRAC maintains a strong reputation. Since 2002, in fact, the organization has been able to expand its work outside of Bangladesh to other developing countries such as Pakistan and Sierra Leone. Looking back at the organization's early years allows us to examine how it established a reputation for competency to sustain donor funding and grow to become one of the largest NGOs in the world. Because BRAC is such a large organization that is involved in a broad spectrum of development activities, we focus on two specific programs: BRAC's initial relief effort in Sulla and its non-formal primary education (NFPE) program.

BRAC's rehabilitation efforts in Sulla, a remote area in northeastern Bangladesh, serve as a compelling example because this was the organization's first endeavor. Thus, BRAC was a clean slate on which we are able to evaluate the development of a reputation. Additionally, BRAC had a single primary donor at the outset, Oxfam. We are able to track Oxfam's reaction to BRAC's success in Sulla to show the dynamics of reputation in the donor-NGO relationship. In early 1972, BRAC applied for and received funding from Oxfam to assist the resettlement of refugees in Sulla. BRAC was at the forefront of relief and reconstruction efforts in the region (Korten 1980). By October of 1972, Abed wrote a report for Oxfam to describe what BRAC had accomplished with donor funds in the organization's first nine months. While BRAC's goal was to build 10,500 homes, it had managed to build more than 14,000. Moreover, BRAC offered to return leftover money to Oxfam. ${ }^{6}$ BRAC's first endeavor in Sulla, a clear success for the new NGO, signaled competence to their main donor, Oxfam, and spurred immediate additional funding from Oxfam to take part in further development

\footnotetext{
${ }^{6}$ The gesture of offering money back to Oxfam shocked the donor. Oxfam allowed BRAC to keep the money and use it on future projects (a signal that the donor, Oxfam, perceived BRAC as a competent organization) (Smillie 2009, 26).
} 
projects (Smillie 2009, 25-27). This success also encouraged BRAC to broaden its goal from resettlement to sustainable community development.

The second example from BRAC's history is its NFPE program. Established in 1985, BRAC's primary goal in pursuing the NFPE program was to increase access to basic education in unreached populations and to improve the quality of that education (BRAC 2013). This second example illustrates the dynamics of reputation building; the NFPE program grew as BRAC's reputation solidified. In 1985 BRAC opened twenty-two one-room schoolhouses in an attempt to extend quality education to children from the poorest families in the country, those "unreachable" children who had been deprived of education because of poverty or gender (Lovell and Fatema 1989, 8). ${ }^{7}$ In classes capped at thirty-three children, students are trained so that they have the ability to enter secondary school (Archer 1994, 225). The school experiment was deemed a success, and by 1987, BRAC was ready to expand the program to 642 schools (Smillie 2009). The rapid growth of the program continued as BRAC continued to demonstrate tangible successes in the education sector. BRAC has consistently signaled positive policy progress by highlighting its low drop out rates and high graduation rates. By 1995, for example, BRAC had opened 19,000 schools, graduating more than 500,000 children (Smillie 2009, 162). Moreover, NFPE has had just a two percent drop out rate and approximately ninety percent of graduates continue on to formal primary schools (Archer 1994, 225). ${ }^{8}$ By emphasizing these tangible successes to donors, BRAC has signaled its competence in the education sector thus ensuring continuous and increased funding from its donor consortium and the continued expansion of NFPE. ${ }^{9}$

The aforementioned examples of BRAC's actions in Bangladesh provide an illustration of how an NGO interacts with donors to establish and develop a reputation. As a new organization in Sulla, BRAC surpassed its goals as set forth to Oxfam and finished under-

\footnotetext{
${ }^{7}$ Criteria for entering the program include having illiterate parents who own less than 0.5 hectares of land (0.5 hectares is equal to about 1.24 acres) (Archer 1994, 225).

${ }^{8}$ This drop out rate can be compared to one that is close to fifty percent by class 5 and over eighty percent by class 10 for those who attend government-run public schools (BRAC 2013).

${ }^{9}$ Donors for BRAC's NFPE program include the Department for International Development (DFID), the Canadian International Development Agency (CIDA), and the European Commission (Boyle 2002).
} 
budget. This action illustrated organizational competence, secured a second year of increased funding, and gave BRAC the opportunity to continue its work toward poverty-reduction and development. The example of the NFPE program illustrates how reputations are dynamic and can grow over time. As BRAC used tangible outcomes, such as graduation rates, to signal its capabilities and competence to donors, it was able to vastly expand its program. Growth has occurred as a result of donor support; BRAC secured increased donor support because donors recognized these successes as signals of BRAC's competence.

BRAC, in fact, has been so successful over the years at illustrating competence and implementing effective development programs that the organization has been able to transition away from a donor dependent financial system. While many donor-NGO relationships create a trap in which NGOs must pursue short-term tangible goals that demonstrate competence to secure funding at the expense of broader long-term aspirations, BRAC has been able to remove itself from this trap. BRAC's leadership realized "early on that self-reliance for its target groups and self-reliance for the organization went hand in hand" (Viravaidya and Hayssen 2001, 9). Thus, BRAC's programs "that generate surpluses above their ongoing costs are used to cross-subsidize other valued programs" (Viravaidya and Hayssen 2001, 9).

More specifically, BRAC operates eighteen financially profitable social enterprises that have helped to mitigate the reputation trap. The first of these enterprises, Aarong, was established in 1978 to market hand-spun silk on a larger scale. ${ }^{10}$ Aarong has been a means of empowering and employing impoverished women and artisans, and it has also brought profits to the organization which have been used to fund the expansion of Aarong, BRAC's other social enterprises, and many of BRAC's development programs. Over the years, BRAC has expanded its social enterprises to include industries such as dairy, fisheries, poultry, salt, and printing (BRAC 2013). BRAC's enterprises serve a dual purpose of development and profit. The enterprises have created hundreds of thousands of jobs and opportunities for the poor (Smillie 2009, 250). Moreover, the BRAC enterprises have been very effective in cutting

\footnotetext{
${ }^{10}$ Aarong has expanded vastly since its inception and now operates 12 retail chain outlets across Bangladesh (BRAC 2013).
} 
BRAC's reliance on donors. By 2011, only twenty-four percent of BRAC's expenditures came from donors as opposed to one hundred percent in 1980 (BRAC 2013). Because BRAC is less reliant on donors, it has been able to partake in longer-term initiatives to further development and poverty reduction in Bangladesh. BRAC's education programs, for example, are now funded and planned on a five-year basis, as opposed to the initial two-year plan of the NFPE. Optimistically, then, the BRAC case demonstrates that NGOs do have an exit option from the adverse incentives caused by the donor-NGO relationship.

\section{Conclusion}

Our central conclusion is connected to the fundamental principal-agent relationship between donors and NGOs. The inability of donors to accurately and consistently observe competence in the NGOs they support creates a political hurdle for NGOs as they seek to maintain funding in order to pursue their policy goals. Because an NGO's competence is both private information and dynamic over time, NGOs are forced to divert energy and resources to developing and maintaining a reputation for competence. This incentive can cause NGOs to invest higher levels of effort in policy activities that will consistently deliver tangible evidence of progress in order to credibly signal competence to their donors.

One interesting implication of the model is the rational explanation of what may appear to be wasteful or short-sighted behavior on the part of NGOs. These organizations are routinely criticized for working on what appear to be small, temporary, and perhaps even counterproductive accomplishments. In the area of international mediation, for example, signing a cease-fire agreement is a far cry from implementing the agreement to obtain peace. Nevertheless, the peace agreement is championed by the mediator as a mediation success story. Similarly, environmental NGOs may organize multi-party talks that produce non-binding agreements that unravel almost as quickly as they are produced, yet such agreements are announced with much fanfare and seemingly naive expectations of compliance. Water NGOs may find themselves counting on temporary solutions as they struggle 
to gather enough resources to tackle their long term goals of sanitation, water quality, and access. These behaviors may simply be an effort by NGOs to communicate meaningful signals of competence to their donors. Ironically, even when these activities detract from the overall mission of the NGO, it will feel compelled to divert resources to consistent and public demonstrations of tangible progress in an effort to preserve funding. In other words, an NGO can find itself in a reputation trap.

By stepping away from the traditional focus between NGO and its clients and shifting our perspective to the role of reputation in the relationship between donor and NGO, we offer a perspective that sheds new light on NGO behavior. Without making heroic or cynical assumptions about the intentions of NGOs, we demonstrate that these organizations balance their normative goals with the strategic survival imperatives that emerge from the NGOdonor relationship. This balancing act has important implications for policy behavior.

Overcoming this tradeoff cannot be accomplished strictly through improvements in transparency and accountability (the two most common calls for NGO reform), but it would be a mistake to conclude that this structural problem cannot be solved. As the BRAC illustration shows us, one path NGOs can take to avoid the constant demands to maintain one's reputation involves changing the organizations dependence on donors (i.e., self-sustainability). Another path could be to try to convince donors that the NGO's competence is established and invulnerable to change. Reputation stability, if possible, would relieve the NGO's need to re-demonstrate its competence to donors. This condition may be most likely to be achieved by changing the duration of funding agreements. Longer funding cycles give NGOs more time to accomplish their goals without focusing on survival. Just as a U.S. senator has more freedom to take political risks and focus on long term problems than her counterparts in the House of Representatives, NGOs with a multi-year funding guarantee have more leeway than those who face yearly renewals. Such a solution of course introduces potential accountability problems, but we argue that this is at least a tradeoff that needs to become a part of the policy discussion. 


\section{Appendix: Proof of Proposition 1}

Proof. Assume that $\lambda>0$ and $f / \pi>\hat{\mu}$. Consider the case where the competent NGO always chooses high effort. In a Markov perfect equilibrium, strategies are only dependent upon payoff relevant histories, so they will be a function of the donor's belief about the NGO's competence $(\mu)$. The donor will prefer to fund if $p(\mu)=\mu \pi \geq f$. Thus, donor will fund in a given period if $\mu \geq f / \pi \equiv \mu^{*}$ and not fund otherwise. In any period in which donor's belief is less than $\mu^{*}$, the NGO will not be funded and will cease to exist. Since $f / \pi>\hat{\mu}$, there exist potential beliefs Let $k_{j}$ be a state in which after $j$ consecutive unsuccessful outcomes, the donor will not fund the NGO, and let $K_{j}$ be the set of all $k_{j}$ for a given $j$. (For example, if the current state is $k_{1}$, then $\mu \geq \mu^{*}$ and $\mu_{u}<\mu^{*}$.) Let $k_{s}$ be a state in which there was a successful outcome in the previous period. Then, $\left\{K_{0}, K_{1}, K_{2}, \ldots, K_{s}\right\}$ is a partition of the true state space, the interval of possible values of $\mu$ : $[\hat{\mu}, 1-\lambda(1-\theta)]$. Given the donor's strategy, a Markov strategy for the NGO can be defined as a function $\sigma:\left\{k_{0}, k_{1}, k_{2}, \ldots, k_{s}\right\} \rightarrow[0,1]$.

Consider $k_{0}$. Given the competent NGO's strategy, the continuation values are:

$$
\begin{aligned}
& V_{C}\left(k_{1}\right)=-e+\delta[1-\lambda(1-\theta)] \pi V_{C}\left(k_{s}\right)+\delta \lambda(1-\theta) \pi V_{I}\left(k_{s}\right), \\
& V_{I}\left(k_{1}\right)=0 .
\end{aligned}
$$

For $k_{1}$, the continuation values are:

$$
\begin{aligned}
& V_{C}\left(k_{1}\right)=f-e+\delta[1-\lambda(1-\theta)] \pi V_{C}\left(k_{s}\right)+\delta \lambda(1-\theta) \pi V_{I}\left(k_{s}\right), \\
& V_{I}\left(k_{1}\right)=f .
\end{aligned}
$$


For $j>1$, the continuation values are:

$$
\begin{aligned}
V_{C}\left(k_{j}\right)=f & -e+\delta[1-\lambda(1-\theta)]\left[\pi V_{C}\left(k_{s}\right)+(1-\pi) V_{C}\left(k_{j-1}\right)\right] \\
& +\delta \lambda(1-\theta)\left[\pi V_{I}\left(k_{s}\right)+(1-\pi) V_{I}\left(k_{j-1}\right)\right] \\
V_{I}\left(k_{j}\right)=f & +\delta(1-\lambda \theta) V_{I}\left(k_{j-1}\right)+\delta \lambda \theta V_{C}\left(k_{j-1}\right) .
\end{aligned}
$$

For $j>1$, given $k_{j}$, NGOs will receive funding with certainty in the next period regardless of the policy outcome. Thus, $V_{\tau}\left(k_{j}\right)>V_{\tau}\left(k_{1}\right)$ for $j>1$ and $\tau \in\{C, I\}$. Since $V_{\tau}\left(k_{2}\right)>$ $V_{\tau}\left(k_{1}\right)$, it follows that $V_{\tau}\left(k_{3}\right)>V_{\tau}\left(k_{2}\right)$. By this same logic, one can show that $V_{\tau}\left(k_{j}\right)>$ $V_{\tau}\left(k_{j-1}\right)$ for $j \leq s$.

Now consider the competent NGO's strategy. For $k_{0}$ and $k_{1}$, its value for deviating in a given period and choosing low effort is $V_{C}\left(k_{0} \mid L\right)=0$ and $V_{C}\left(k_{1} \mid L\right)=f$, respectively. Thus, in both cases, the competent NGO will choose high effort if $V_{C}\left(k_{j}\right) \geq V_{C}\left(k_{j} \mid L\right)$, or

$$
e \leq \delta[1-\lambda(1-\theta)] \pi V_{C}\left(k_{s}\right)+\delta \lambda(1-\theta) \pi V_{I}\left(k_{s}\right)
$$

For $j>1$,

$$
V_{C}\left(k_{j}\right)=f+\delta[1-\lambda(1-\theta)] V_{C}\left(k_{j-1}\right)+\delta \lambda(1-\theta) V_{I}\left(k_{j-1}\right) .
$$

Thus, the competent NGO will choose high effort if

$$
e \leq \delta[1-\lambda(1-\theta)] \pi\left[V_{C}\left(k_{s}\right)-V_{C}\left(k_{j-1}\right)\right]+\delta \lambda(1-\theta) \pi\left[V_{I}\left(k_{s}\right)-V_{I}\left(k_{j-1}\right)\right]
$$

Since $V_{\tau}\left(k_{j}\right)>V_{\tau}\left(k_{j-1}\right)$ for $j \leq s$ and $\tau \in\{C, I\}$, the right hand side of (11) is always positive and decreasing in $j$. Thus, if the competent NGO will prefer to choose high effort in $k_{s}$, it will choose high effort in all other states. Thus, the competent NGO will choose 
high effort if $e \leq e^{*}$, where

$$
e^{*}=\delta[1-\lambda(1-\theta)] \pi\left[V_{C}\left(k_{s}\right)-V_{C}\left(k_{s-1}\right)\right]+\delta \lambda(1-\theta) \pi\left[V_{I}\left(k_{s}\right)-V_{I}\left(k_{s-1}\right)\right]>0 .
$$




\section{References}

Adams, Jerry. 2001. "NGOs and Impact Assessment." NGO Policy Briefing Paper (3).

Archer, David. 1994. "The changing roles of non-governmental organizations in the field of education (in the context of changing relationships with the state)." International Journal of Educational Development 14(3):223-232.

Barakat, Sultan, David Connolly and Judith Large. 2002. "Winning and Losing in Aceh: Five Key Dilemmas in Third-Party Intervention." Civil Wars 5(4):1-29.

Barnett, Michael N. and Martha Finnemore. 1999. "The politics, power, and pathologies of international organizations." International Organization 53(4):699-732.

Barnett, Michael N. and Martha Finnemore. 2004. Rules for the world: international organizations in global politics. Cornell University Press.

Beardsley, Kyle. 2011. The Mediation Dilemma. Cornell University Press.

Bercovitch, Jacob and Gerald Schneider. 2000. "Who Mediates? The Political Economy of International Conflict Management." Journal of Peace Research 37(2):145-165.

Bercovitch, Jacob and Richard Jackson. 2009. Conflict resolution in the twenty-first century: principles, methods, and approaches. University of Michigan Press.

Boulding, Carew. 2009. "Accountability in Foreign Aid Delivery: Links between Donors and NGOs." Working Paper .

Boyle, Roisin. 2002. "Aid Coordination in Non-formal Primary Education: A Case Study in Bangladesh Focusing on BRAC and Proshika." Forum of International Development Studies 22:125-160.

BRAC. 2013. www. brac.net/ (January 21, 2013). 
Calow, R.C., N.S. Robins, A.M. MacDonald, D.M.J. MacDonald, B.R. Gibbs, W.R.G. Orpen, P. Mtembezeka, A.J. Andrews and S.O. Appiah. 1997. "Groundwater Management in Drought-Prone Areas of Africa." Journal of Water Resources Development 13(2):241-262.

Carter, Richard C., Sean F. Tyrrel and Peter Howsam. 1999. "Impact and Sustainability of Community Water Supply and Sanitation Programmes in Developing Countries." Journal of the Chartered Institution of Water and Environmental Management 13:292-296.

Chowdhury, AMR and Abbas Bhuiya. 2001. "The Wider Impacts of BRAC Poverty Alleviation Programme in Bangladesh." Journal of International Development 16:369-386.

Cooley, Alexander and James Ron. 2002. "The NGO Scramble: Organizational Insecurity and the Political Economy of Transnational Action." International Security 27(1):5-39.

Copeland, Dale C. 1997. "Do reputations matter?" Security Studies 7(1):33-71.

Crescenzi, Mark J. C. 2007. "Reputation and Interstate Conflict." American Journal of Political Science. 51(2):382-396.

Crescenzi, Mark J. C., Jacob.D. Kathman and Stephen B. Long. 2007. "Reputation, History, and War." Journal of Peace Research 44(6):651-667.

Crescenzi, Mark J.C., Jacob D. Kathman, Katja B. Kleinberg and Reed M. Wood. 2012. "Reliability, Reputation, and Alliance Formation." International Studies Quarterly 56(2):259274.

Diehl, Paul F. and J. Michael Grieg. 2012. International Mediation. Polity Press.

Ebrahim, Alnoor. 2002. "Information Struggles: The Role of Information in the Reproduction of NGO-Funder Relationships." Nonprofit and Voluntary Sector Quarterly 31(1):84114.

Ebrahim, Alnoor. 2003. "Accountability In Practice: Mechanisms for NGOs." World Development 31(5):813-829. 
Ebrahim, Alnoor. 2005. "Accountability Myopia: Losing Sight of Organizational Learning." Nonprofit and Voluntary Sector Quarterly 34(1):56-87.

Edwards, Michael and David Hulme. 1996. "Too Close for Comfort? The Impact of Official Aid on Nongovernmental Organizations." World Development 24(6):961-973.

Finnemore, Martha. 1996. "Norms, culture, and world politics: insights from sociology's institutionalism." International organization 50(02):325-347.

Fudenberg, D. and D.K. Levine. 1989. "Reputation and equilibrium selection in games with a patient player." Econometrica: Journal of the Econometric Society pp. 759-778.

Fudenberg, D. and D.K. Levine. 1992. "Maintaining a reputation when strategies are imperfectly observed." The Review of Economic Studies 59(3):561-579.

Gleitsmann, Brett A, Margaret M. Kroma and Tammo Steenhuis. 2007. "Analysis of a rural water supply project in three communities in Mali: Participation and sustainability." Natural Resources Forum 31:142-150.

Gugerty, Mary Kay. 2009. "Signaling Virtue: Voluntary Accountability Programs among Nonprofit Organizations." Policy Sci 42:243-273.

HDC Annual Report. 2009. www.hdcentre.org/publications (August 1, 2012).

Huber, Konrad. 2004. The HDC in Aceh : promises and pitfalls of NGO mediation and implementation. East-West Center Washington, Washington, D.C. http://www.eastwestcenterwashington.org/publications/psseriespdf9.htm.

Jervis, Robert. 1976. Perception and Misperception in International Politics. Princeton, New Jersey: Princeton University Press.

Jervis, Robert. 1988. "War and Misperception." Journal of Interdisciplinary History 18(4):675-700. 
Johnson, Erica and Aseem Prakash. 2007. "NGO Research Program: A Collective Action Perspective." Policy Sci 40:221-240.

Jordan, Lisa. 2005. "Mechanisms for NGO Accountability." GPPi Research Paper Series No. 3, Global Public Policy Institute: Berlin.

Keohane, Robert O. 1984. After Hegemony: Cooperation and Discord in the World Political Economy. Princeton, NJ: Princeton University Press.

Korten, David C. 1980. "Community Organization and Rural Development: A Learning Process Approach." Public Administration Review 40(5):180-511.

Kreps, D.M. and R. Wilson. 1982. "Reputation and imperfect information." Journal of economic theory $27(2): 253-279$.

Leary, Kimberlyn. 2004. "Critical Moments as Relational Moments: The Centre for Humanitarian Dialogue and the Conflict in Aceh, Indonesia." Negotiation Journal 20(2):311-338.

Levy, Jack S. 1994. "Learning and Foreign Policy: Sweeping a Conceptual Minefield." International Organization 48(2):279-312.

Mailath, George J. and Larry Samuelson. 1998. "Your Reputation is Who You're Not, Not Who You'd Like to Be." Working Paper.

Mailath, George J. and Larry Samuelson. 2001. "Who Wants a Good Reputation?" Review of Economic Studies 68:415-441.

Mercer, Jonathan. 1996. Reputation and International Politics. Ithaca, NY: Cornell University Press.

Milgrom, P. and J. Roberts. 1982. "Predation, reputation, and entry deterrence." Journal of economic theory 27(2):280-312. 
Morfit, Michael. 2007. "The Road to Helsinki: The Aceh Agreement and Indonesia's Democratic Development." International Negotiation 12:111-143.

Najam, Adil. 1996. "NGO Accountability: A Conceptual Framework." Development Policy Review 14(4):339-353.

O’Dwyer, Brendan and Jeffrey Unerman. 2007. "From Functional to Social Accountability: Transforming the Accountability Relationship between Funders and Non-governmental Development Organisations." Accounting, Auditing $\&$ Accountability Journal 20(3):446471.

O’Dwyer, Brendan and Jeffrey Unerman. 2008. "The Paradox of Greater NGO Accountability: A Case Study of Amnesty Ireland." Accounting, Organizations and Society 33(78):801-824.

Press, Daryl Grayson. 2004. "The Credibility of Power: Assessing Threats during the "Appeasement" Crises of the 1930s." International Security 29(3):136-169.

Reinhardt, Gina Yannitell. 2009. "Matching Donors and Nonprofits: the Importance of Signaling in Funding Awards." Journal of Theoretical Politics 21(3):283-309.

Schelling, Thomas. 1966. Arms and Influence. New Haven, CT: Yale University Press.

Schulze, Kirsten E. 2004. The Free Aceh Movement (GAM): Anatomy of a Separatist Organization. East-West Center Washington, Washington, D.C.

Skinner, Jamie. 2009. "Where Every Drop Counts: Tackling Rural Africa's Water Crisis." IIED Briefing Papers . http://pubs.iied.org/pdfs/17055IIED.pdf.

Smillie, Ian. 2009. Freedom from Want:The Remarkable Success Story of BRAC, the Global Grassroots Organization That's Winning the Fight Against Poverty. Kumarian Press.

Sundstrom, Lisa McIntosh. 2005. "Foreign Assistance, International Norms, and NGO Development: Lessons from the Russian Campaign." International Organization 59(2):419-449. 
Viravaidya, Mechai and Jonathan Hayssen. 2001. "Strategies to Strengthen NGO Capacity in Resource Mobilization through Business Activities." UNAIDS Best Practice Collection

Walter, Barbara F. 2003. "Explaining the Intractability of Territorial Conflict." International Studies Review 5(4):137-153.

Walter, Barbara F. 2006. "Building Reputation: Why Governments Fight Some Separatists but Not Others." American Journal of Political Science 50(2):313-330.

Waltz, Kenneth. 1979. Theory of International Politics. New York, NY: Random House.

WaterAid. 2010. "WaterAid in Ghana: Country programme evaluation." WaterAid: Briefing Note. https://www.wateraid.org/documents/plugin_documents/ wagh20briefing20note.pdf.

WaterAid. 2012. "WaterAid America Annual Report 2011/12.". http://www . wateraidamerica.org/includes/documents/cm_docs/2012/w/2_wateraid_in_ america_annual_report_201112.pdf. 